

\section{HABLANDO DE DISEÑO...}

Joan Costa

Universidad Autónoma de Barcelona Istituto Europeo di Design

UNO DE LOS VIEJOS TEMAS RECURRENTES QUE DE VEZ EN CUANDO SE PONEN DE ACTUALIDAD PARA DESVANECERSE Y REAPARECER, Y ASÍ SUCESIVAMENTE, ES LA CUESTIÓN -SIEMPRE MAL FORMULADA- DE SI EL DISEÑO ES ARTE. DEBATIMOS ESTA CUESTIÓN EN UN

$-i \mathrm{E} 1$ diseño es arte?

- No, querida. Diseño es diseño.

- No me negarás que el arte y el diseño tienen mucho en común....

- También tú y yo tenemos mucho en común, pero somos diferentes. Lo que tenemos en común pertenece a la especie. Pero lo que define nuestra identidad como individuos únicos e irrepetibles no es lo que tenemos en común, sino justo lo que nos es propio psicológica y culturalmente.

La teoría de la Forma ya nos enseñó que la percepción asocia lo que se parece. Pero cuando vas más allá de la percepción en busca de un conocimiento, y encuentras una sola diferencia, entonces sigue observando y descubrirás más y más diferencias. Las únicas semejanzas entre arte y diseño son puramente formales. Pero La Gioconda y la marca de Mercedes son algo más que formas.

- Pues no deben ser muy diferentes, porque hay artistas que hacen diseño y diseñadores que hacen arte.

- Uno puede hacer muchas cosas distintas, pintar un cuadro, diseñar un cartel, cocinar y jugar al ajedrez. Lo esencial de tu pregunta no es la persona que hace la cosa, sino la cosa que hace esta persona: ¿arte o diseño? 0 más exactamente: lo que interesa es la naturaleza de esas cosas.

-Tú dirás lo que quieras, pero hay diseños que tienen valores artísticos innegables.

- "Lo artístico" no es el arte. Leonardo, Van Gogh 
- Picasso no son"artísticos". El adjetivo "artístico" está ligado al acto de la creación. Pero estamos hablando de sustantivos y con mayúscula: Arte y Diseño. Desconfía del adjetivo "artístico" cuando se aplica a algo que no es arte. Pero desconfía también del "diseño" como adjetivo: muebles de diseño, ropa de diseño, peluquerías de diseño o drogas de diseño.

- Entonces, si hablamos de arte, itenemos que pensar en belleza, en una cierta poética?...

- La belleza o la poética es lo que a menudo es la razón de la obra de arte. La belleza, o incluso la fealdad, es al arte lo que la estética es al diseño. Pero una estética funcional. El diseño no es arte pero vive de él porque se alimenta de sus diferentes estéticas. De ahí vienen las confusiones.

- Pues yo comparo diseño con Kandinsky, Klee y Mondrian.

- ¿Y por qué no con Rubens, El Greco o Grünewald?

- Pues porque no tienen nada que ver.

- iCómo que no! ¿ No hablamos de arte?

- Sí pero no del arte clásico.

- Entonces tu pregunta está mal formulada o plantea un falso problema. En cualquier caso, ¿a qué arte te refieres? Si lo que piensas es si el diseño es arte postimpresionista, o expresionista, o informalista, o surrealista, entonces la pregunta todavía tiene menos sentido.

- Pues vamos a darle la vuelta. ¿Bacon, el cubismo, una performance y una instalación son arte?

- Sí. Son expresiones distintas de lo esencial.

- ¿Y qué es lo esencial?

- Lo esencial es que el arte se hace preguntas y el diseño soluciona problemas.

El cubismo, la abstracción no son experimentos, son cuestionamientos sobre la vida, el mundo, nuestras ideas sobre todo esto, la sociedad, los valores, la mente humana.

- ¿Preguntas sobre la mente?

- Sí, sobre la naturaleza humana. Tú sabes que la geometría, la matemática, el espacio y el tiempo no están en el entorno, sino en nuestro modo de percibirlo $y$ de concebirlo. Están en nuestro cerebro. El arte cubista proyecta formas mentales en la representación pictórica 
del mundo. $Y$ estas formas son geométricas porque salen de dentro, no están afuera. Los pintores divisionistas o puntillistas tuvieron una intuición genial sobre la naturaleza de la luz, de la visión y de la percepción del color. Cuando Kandinsky, Klee o Mondrian cierran los ojos a la realidad externa y miran hacia adentro, su lenguaje plástico es la forma pura (el "signo absoluto" como decía Walter Benjamin), la geometría, el color puro, el signo gráfico, el punto, la línea. En la Naturaleza no hay líneas ni contornos, pero sí están en la naturaleza del signo, el dibujo y la escritura.

- Decir signo, dibujo y texto es hablar de diseño.

- Hablo de grafismo, que no es lo mismo. Grafismo es el universo de "lo gráfico", lo que los griegos llamaron graphein cuando encontraron, en la mano humana, la raíz común del dibujo y el escrito.

- Por eso hablamos de arte gráfico.

- Es bien cierto que hay arte gráfico y también diseño gráfico. El primero es el dibujo y el grabado de las Bellas Artes. El segundo es la praxis que nació con la imprenta gutenberguiana, el dibujo de los tipos de letra, la composición de la página impresa (por cierto, con la "proporción áurea" o el "número de oro", que definían la arquitectura de la página impresa, es decir, una síntesis de la geometría y la matemática: cosas mentales). Después vino el cartel, que ya no está emparentado con el dibujo sino con la pintura. Que no es el mundo de la línea sino de la mancha. Luego vendría la Bauhaus en pleno industrialismo, que convirtió la praxis artesana del diseño al rango de disciplina.

Arte gráfico y diseño gráfico tienen en común el graphein, es decir, el origen, que no es otro que la mano que "traza". Pero uno sigue siendo arte y el otro diseño.

- Siguiendo tus razonamientos sobre las diferencias, también podríamos añadir que el diseñador trabaja para un cliente que le paga y juzga su trabajo.

- Es así pero sólo hasta cierto punto, porque también grandes artistas eran pagados ya fuera por donantes, mecenas o cortesanos. Lo que es esencial aquí no es que el diseñador reciba dinero por su trabajo, lo cual es justo, sino que quien le paga -su cliente- le impone el objetivo, el fin, la función de lo que ha de hacer e incluso lo que debe conseguir. No le dirá cómo debe hacerlo (éste es el 
campo de libertad del diseñador), sino qué debe hacer para lograr el objetivo de su cliente.

- Ya, el artista es libre. Nadie le impone un objetivo. Esto enlaza con lo que decías sobre la función del diseño, que es resolver problemas.

LA EFICACIA

ES EL OBJETIVO DEL

PRAGMATISMO,

NO DEL ARTE

- Así es. El diseño no tiene otra ideología que la eficacia.

- Bueno, pero imagino que Goya quería ser eficaz...

- La eficacia es el objetivo del pragmatismo, no del arte. El diseñador gráfico busca la eficacia en la solución de un problema de comunicación, igual como el diseñador industrial busca la eficacia en un problema de funciones.

- El objeto industrial también comunica.

- Pero su función primera y esencial no es comunicar. $Y$ sí es comunicar la función primera y esencial del mensaje gráfico. Un objeto no es un mensaje. Y si decimos que un objeto como unas tijeras o un zapato comunican es porque todo lo que es visible, toda forma, significa.

- Si el diseño es comunicación, el arte también es comunicación, del artista con el público.

- Y hablar por teléfono también es comunicación. Pero insisto. Lo esencial no es que todo lo que percibimos comunique, cada cosa a su manera, sino qué es lo que se está comunicando. $Y$ sobre todo, para qué. El diseñador quiere seducirte para que compres un producto, para meter una marca en tu cabeza, para que votes a un candidato o para que no te extravíes por los laberintos de monstruosos aeropuertos como el de Madrid Barajas. Estas son funciones del diseño. Que bien poco tienen que ver con el arte. Porque el artista no se conforma al mundo sino que se le opone.

- Sin embargo, los diseñadores no han cesado de preguntarse si el diseño es arte, ¿́por qué, entonces?

- Yo veo en esta fijación del diseñador gráfico una parte de nostalgia histórica. El artista nunca se pregunta si eso que está haciendo será diseño. Tampoco los otros profesionales del diseño cuando diseñan una cafetera, un tractor o un frigorífico se preguntan si acaso están haciendo arte. Esto tampoco se lo plantean Calvin Klein o Toni Miró. Y veo aquí otro signo, un tanto freudiano, que revela la frustración de muchos diseñadores gráficos, que empezaron soñando con ser artistas y han acabado siendo 
operadores. Pero siguen empeñados en meter el arte en su trabajo como sea, y hablan de "arte final" y de "dirección de arte". ¿Por esnobismo o por consolarse?

- Palabras....

- En el mundo del diseño, que es un mundo de símbolos, las palabras son fundamentales. La palabra diseño está muy connotada del disegno del Renacimiento italiano, que significa, como quería Vasari, el Dibujo, "el padre de nuestras tres artes: Arquitectura, Escultura y Pintura".

Por el contrario, la palabra design es más precisa. Corresponde claramente al industrialismo nacido en Inglaterra, a la cultura técnica, que es la nuestra nos guste o no.

- Dime, ¿cuándo nace el arte?

- En la prehistoria, con el sentimiento simbólico de sapiens, que no sabía lo que era arte.

- ¿Y el diseño?

- En el Renacimiento germano-italiano. Nace como grafismo con la imprenta gutenberguiana, o sea, a través de un medio técnico de producción. Y se consagra como diseño con la Bauhaus, en plena revolución industrial. E1 diseño (design) es hijo de la economía de producción.

- No sé si me has convencido, pero me has dado mucha materia para pensar.

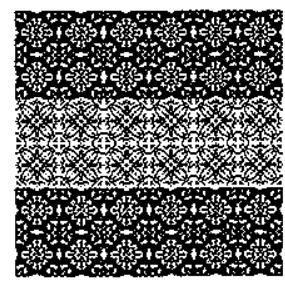

